\title{
ALEIJANDO AS POLÍTICAS QUEER, OU OS PERIGOS DO NEOLIBERALISMO ${ }^{1}$
}

Robert McRuer ${ }^{2}$

Resumo: Neste texto seminal, Robert McRuer aponta para as armadilhas neoliberais que estão presentes em determinadas formas de ativismos pautados em identidades. McRuer, a partir de ferramentas teóricas e analíticas circunscritas entre a teoria queer e crip, discute como é preciso observar os contextos materiais em que certas identidades se perfazem positivamente em detrimento de outras.

Palavras-chave: ativismo.; deficiência; Igbtqi+; neoliberalismo; política queer.

1 Tradução de Marco Antônio Gavério. Revisão da tradução de Anahí Guedes de Mello e Giovanna Marafon. Agradecemos ao Professor Robert McRuer pela autorização da tradução de seu texto, bem como agradecemos às editoras do periódico The Scholar \& Feminist Online.

2 NT: Robert McRuer é professor de Inglês da Universidade George Washington, EUA. McRuer é reconhecido como um dos teóricos que fundamentam as discussões entre as críticas sobre deficiência e sexualidade a partir da teoria Crip. Dentre suas principais obras estão: "The Queer Renaissance, Contemporary American Literature and the Reivention of Lesbian and Gay Identities. New York: New York University Press, 1997", "Crip Theory: Cultural Signs of Queerness and Disability" (McRuer, 2006) e "Crip Times: Disability, Globalization, and Resistance. Crip: New Directions in Disability Studies Series. New York: New York University Press, 2018”. E-mail: rmcruer@gwu.edu 


\section{CRIPPING QUEER POLITICS, OR THE DANGERS OF NEOLIBERALISM}

Abstract: In this seminal text, Robert McRuer points to the neoliberal traps that are present in certain forms of activism based on identities. McRuer, based on theoretical and analytical tools circumscribed between queer and crip theory, discusses how it is necessary to observe the material contexts in which certain identities are positively at the expense of others.

Keywords: activism; deficiency; Igbtqi +; neoliberalism; queer politics.

\section{LA POLÍTICA QUEER TULLIDA, O LOS PELIGROS DEL NEOLIBERALISMO}

Resumen: En este texto seminal, Robert McRuer señala las trampas neoliberales que están presentes en ciertas formas de activismo basado en identidades. McRuer, a partir de herramientas teóricas y analíticas circunscritas entre la teoría queer y crip, discute cómo es necesario observar los contextos materiales en los que determinadas identidades están positivamente a expensas de otras.

Palabras clave: activismo; discapacidad; Igbtqi+; neoliberalismo; política queer. 


\section{Introdução}

Algumas das políticas contemporâneas da deficiência mais combativas estão intimamente relacionadas a uma variedade de ativismos queer ${ }^{3}$ das últimas décadas. Naturalmente, muitos que se auto identificam como "aleijados"4 - termo cada vez mais adotado em todo o espectro da deficiência, não apenas por pessoas com deficiência física ou mobilidade reduzida [mobility impairments] - também se identificam como queer. Muitos outros insistiriam que a desafiadora reinvenção e reivindicação do aleijado está ligada à reinvenção crítica - por ativistas, artistas e estudiosos - do queer. Mais importante ainda, os ativismos queer e aleijado compartilham uma vontade de refazer o mundo, dadas as maneiras em que a injustiça, a opressão e as hierarquias são construídas (muitas vezes literalmente) nas estruturas da sociedade contemporânea.

Para os ativistas aleijados, a vontade de refazer o mundo manifesta-se de várias maneiras. "Torne acessível ou mijaremos em qualquer lugar", exclama um adesivo. Esta proposta explicitamente aleijada, feita para ser colada em edifícios e outros locais que não são acessíveis a pessoas com deficiência, transforma o espaço trazendo à luz as exclusões que o estruturam. Um espaço que parece aberto a qualquer pessoa que o ocupe é exposto como constituído por noções muito rígidas de abertura e aceitação. Corpos e práticas corporais percebidas como não normativos são constantemente posicionados fora do que se considera "publicamente" habitável nesses espaços e, através de uma mistura de raiva extravagante e humor camp ${ }^{5}$, o adesivo, como muitas

\footnotetext{
${ }^{3}$ NT: o termo possui uma considerável variabilidade semântica quando transposto para a língua portuguesa, podendo ser traduzido como torção, estranho, esquisito, aberrante. Entretanto, dentro do escopo desse artigo, o queer é referente à contra identificação estratégica daqueles e daquelas considerados desviantes das normatividades sexuais e de gênero. Nesse sentido, o termo queer, antes um xingamento e acusação contra aqueles e aquelas fora das normas e padrões sexuais, torna-se um contra-ataque à própria ordem que divide os indivíduos entre "normais" e "patológicos". Assim, poderíamos pensar uma tradução mais popular para a palavra queer, como transviado, bicha louca, sapatão. Optamos por deixar o termo em seu original devido ao fato de que no Brasil já se convencionou ser aceito e compreensível o queer em inglês.

${ }^{4}$ Tradução livre do termo em inglês crip, que pode ser considerado uma gíria e uma abreviação da palavra cripple. Assim como o termo queer, cripple é considerado um termo derrogatório, uma ofensa voltada às pessoas com deficiência. Como aponta McRuer neste ensaio, o termo cripple tem sido estrategicamente utilizado por parcelas ativistas dos movimentos de pessoas com deficiência para apontar as ordenações normativas da divisão entre indivíduos corporalmente capazes e aqueles considerados disfuncionais ou 'não capazes'. Para maiores considerações ver McRuer (2006), Gavério (2015), Mello (2018) e Mello \& Gavério (2019).

${ }^{5} \mathrm{NT}$ : Esse termo pode ser interpretado como tendo o sentido de extravagante, espalhafatoso, exagerado. Contudo, o camp também é considerado uma estética, uma performance estetizada a partir de certos
} 
intervenções queer nas últimas décadas, nos empurra em direção a culturas públicas mais expansivas.

No nítido espírito aleijado do adesivo ("torne acessível"), este ensaio oferece uma tese relativamente simples: uma política queer vibrante deve incorporar uma política aleijada vibrante (e vice-versa).

No entanto, o projeto de construção dessa solidariedade aleijada/queer não é tão "simples" como poderia parecer. Em particular, o sistema político e econômico atual, chamado pelos teóricos políticos de neoliberalismo (ver o ensaio de Lisa Duggan nesta edição para obter uma descrição do neoliberalismo6), oferece um reconhecimento limitado para representar gays ou deficientes. Este reconhecimento depende de uma aceitação de normas dominantes, mas para diferenças singularizadas no ser gay ou ser deficiente. Assim, por exemplo, Lisa Duggan (2003) argumentou que alguns proponentes de uma versão limitada dos direitos gays construíram uma "homonormatividade"7, que espelha as normas dominantes - branca, de classe média e orientada para a família - mas exceto na diferença singular de parceiros do mesmo gênero nas relações conjugais. Da mesma forma, as pessoas com deficiência que procuram se espelhar na sociedade dominante, mas seguindo uma diferença singularizada na capacidade física pode criar uma política que exclui queers e outros cujas identidades os colocam à parte das normas dominantes da vida familiar branca e de classe média. Tal política de diferenciação singular pode impedir coalizões entre identidades, tais como a solidariedade aleijada/queer que estou defendendo aqui, e também pode prejudicar a organização em torno de temas (pobreza, cuidados de saúde, a destruição do meio ambiente, e assim por diante) não diretamente ligados à identidade.

maneirismos e artifícios que deturpam o que é real e irreal, o que é tradicional e o que é moderno. Nesse sentido, o camp se torna aparentado do que poderia ser chamado de estética queer, isto é, uma forma exagerada, espalhafatosa de mostrar as normatividades em torno do gênero e da sexualidade. Para considerações do camp como estética ver Sontag (1999). Para considerações entre o camp e o queer ver Lopes (2002).

${ }^{6}$ NT: McRuer se refere ao texto "After Neoliberalisn? From Crisis to Organizing for Queer Economic Justice", de Lisa Duggan (2012).

7 NT: Duggan (2003, p. 179, tradução nossa) aponta que a "homonormatividade é uma política que não contesta premissas e instituições dominantes da heteronormatividade, mas as mantém e sustenta enquanto promete a possibilidade de um círculo eleitoral gay desmobilizado e uma cultura gay privatizada e despolitizada, ancorada na domesticidade e no consumo". 
O neoliberalismo é o sistema econômico e cultural dominante do nosso tempo. É um sistema que posiciona o mercado como a resposta para tudo. Qualquer problema é supostamente melhor solucionado - mais eficaz e eficientemente - através do mercado. $\mathrm{O}$ neoliberalismo posiciona a mudança de funções anteriormente públicas para a esfera privada do mercado como um bem inequívoco e com um senso comum inquestionável. Como corolário, quaisquer obstáculos ao funcionamento desse mercado (incluindo barreiras ao fluxo de capital) devem ser eliminados através de vários tipos de desregulamentação. Os proponentes do neoliberalismo defendem a desregulamentação mesmo que ela exija (ou tenha exigido na prática) uma regulação crescente sobre a circulação das pessoas. E o neoliberalismo, enquanto promete uma liberdade sem precedentes e um crescimento desenfreado, exacerba todos os tipos de desigualdades ao redor do globo. A ideologia neoliberal exibe uma genialidade especial ao fazer o crescimento desequilibrado - a riqueza para alguns e a miséria para muitos - parecer sensual, progressista e "moderno".

Esse posicionamento do neoliberalismo como uma regulação mais progressista do que conservadora, e como a onda do desenvolvimento e do futuro, significa que projetos ativistas podem se transformar em veículos de políticas neoliberais e não de mudança social que realmente desafie a distribuição de riqueza/bem-estar e de poder nas sociedades contemporâneas. "O neoliberalismo é", como escrevem Gérard Duménil e Dominique Lévy (2005), "um sistema predatório": é predatório sobre as energias libertadoras que nossos movimentos geraram, as identificações resistentes que formamos, os recursos a que podemos ter acesso e a abertura radical a futuros alternativos que (surgem como um desejo comum e) perpassam os movimentos progressistas $^{8}$.Os movimentos LGBT e da deficiência não estão imunes a esses perigos. As forças culturais e econômicas neoliberais têm enfatizado de forma heterogênea os movimentos LGBT e da deficiência. Por exemplo, o ativismo em nome do casamento entre pessoas do mesmo sexo muitas vezes posiciona as pessoas gays e lésbicas como perfeitos

\footnotetext{
8 Ver também Duggan (2003). Como argumentam Duggan e muitos outros teóricos, o neoliberalismo valoriza a "responsabilidade" pessoal muito acima de qualquer noção mais ampla do bem público ou bem comum. Para Duggan, "privatização" e "responsabilidade" são inquestionavelmente as palavras-chave do neoliberalismo. Muitos teóricos que escrevem na esteira dos livros de Michael Hardt e Antonio Negri $(2000,2004)$ entendem o neoliberalismo como especificamente posicionado contrariamente a uma noção aberta e expansiva do "comum".
} 
sujeitos neoliberais. Como o neoliberalismo depende de soluções privadas para todos os problemas, "a família" assume um papel cada vez mais importante enquanto provedora de bens e serviços, como o trabalho de cuidar dos mais jovens ou velhos. Alguns defensores do casamento homossexual alegremente abraçaram a ideia de que as pessoas gays e lésbicas assumirão essas responsabilidades para suas famílias recém-formadas sem pedir mais nada ao governo do que o direito de se casarem. Tais campanhas estreitamente formuladas em torno do casamento entre pessoas do mesmo sexo não apoiam o direito de desenvolver uma multiplicidade de diferentes tipos de relacionamentos que podem fornecer o trabalho de cuidar, nem apoiam respostas sociais, como o cuidado diário subsidiado pelo governo, ou não chegam à questão de quem deve fornecer esse trabalho. Em outras palavras, quando o casamento entre pessoas do mesmo sexo casamento entre pessoas do mesmo sexo é divulgado em termos neoliberais, seus ativistas estão dispostos a aceitar e até mesmo promover entendimentos privados sobre a necessidade de cuidado em troca da "aceitação" dos relacionamentos gays e lésbicos. $E$ como ambos os movimentos, LGBT e da deficiência, de diferentes maneiras aceitaram esse tipo de destaque e "foram ao mercado", como afirma Alexandra Chasin (2001), estreitaram sua visão política e sacrificaram compromissos e solidariedades que antes os definiam. O desejo de ser diferente (por exemplo, de formar relações de cuidado que não sigam o modelo do casamento heterossexual) é sacrificado pela esperança de aceitação política e de soluções de mercado. Como resultado, a solidariedade com todos aqueles que persistem em fazer as coisas de forma diferente também é prejudicada.

Eu não concordo com alguns autores que argumentam que o movimento LGBT sempre foi sobre respeito e reconhecimento, enquanto negligencia a redistribuição (e a justiça social de forma mais ampla). Mas a uma parcela dominante do movimento LGBT na virada do século definitivamente tem pensado assim, e eu quero pontuar algumas coisas sobre esse fato ${ }^{9}$. Primeiro, dado o atual reconhecimento mensurável que "nós" de fato alcançamos, as pessoas LGBT nem sempre enfrentam um poder homofóbico

\footnotetext{
9 Por exemplo, no capítulo "From Redistribution to Recognition? Dilemmas of Justice in a 'Postsocialist' Age", Nancy Fraser (1997) afirma que nas últimas décadas a "identidade de grupo" e uma política de conquista do "reconhecimento" suplantaram o "interesse de classe" e uma política de combate à exploração. Para a autora, as pessoas LGBT são as representantes principais daquelas que supostamente se movimentaram com base na busca por reconhecimento.
} 
facilmente identificado como "o Estado" ou "a família"; somos, ao contrário, uma parte necessária e material do mundo contemporâneo. Em segundo lugar, nosso reconhecimento e incorporação flexível nesse mundo vem com a expectativa de privatização e consumo, as agências de casamento e registros na Bloomingdale's ${ }^{10}$ transformam-se em planos de aposentadoria privada e em condomínios fechados de propriedade conjunta fornecidos pela Design Within Reach ${ }^{11}$.Em terceiro lugar, e talvez o mais interessante, dado o que muitas vezes foram somente histórias paralelas ${ }^{12}$, o bom sujeito queer da representação dominante está agora o mais distante possível da deficiência, das diferenças corporificadas que podem tornar uma pessoa gay visivelmente diferente da representação dominante ou daquilo que pode exigir o cuidado além daquele que qualquer "família" individual possa fornecer, ou distante de diferenças que podem exigir mudanças nas estruturas sociais - sejam as estruturas físicas do ambiente construído ou as estruturas relacionais do casamento e da família - e não a assimilação nessas estruturas.

Eu poderia e gostaria de reverter essa afirmação e dizer que os movimentos da deficiência enfrentam perigos semelhantes (mesmo que eles não sejam nem de longe tão comentados quanto o são para as pessoas (GBT). Cada vez mais, o movimento da deficiência ou os estudos sobre deficiência enfatizam o reconhecimento dentro dos termos das normas dominantes e a assimilação à corrente dominante, ao invés de enfatizar mudanças fundamentais para a sociedade. $\mathrm{O}$ bom sujeito deficiente é similarmente aquele que está mais distante do queer (isto é, do tipo indisciplinado de estranheza que não pode ser tão facilmente domesticado). Da mesma forma, no nível das questões políticas, uma ênfase dominante nos Estados Unidos sobre o casamento (e também sobre o serviço militar) para as pessoas LGBT emerge através do arrefecimento de questões que poderiam ser mais diretamente compreendidas como deficientes: desemprego, falta de moradia e assistência médica universal. O afastamento de uma

\footnotetext{
${ }^{10}$ NT: Grande rede de lojas de departamento de luxo estadunidense.

${ }^{11} \mathrm{NT}$ : Rede de lojas de móveis e estruturas domésticas de alto padrão, com desenho moderno e ambientalmente amigável.

12 Para uma consideração sobre uma série de maneiras em que a "estranheza" (queerness) e a deficiência têm convergido ao longo do século passado, ver meu livro Crip Theory: Cultural Signs of Queerness and Disability (MCRUER, 2006).
} 
política de HIV/AIDS vibrante focada em expor e combater a opressão institucionalizada, e o direcionamento a um apelo por direitos e reconhecimento do casamento é o melhor exemplo da virada do século desses processos nos Estados Unidos.

O neoliberalismo é um sistema político e econômico com implicações globais; na verdade, o neoliberalismo está intimamente associado à "globalização", à crescente interrelação dos sistemas econômicos e políticos além das fronteiras de qualquer EstadoNação individual ${ }^{13}$. Instituições globais como o Fundo Monetário Internacional (FMI) e o Banco Mundial são algumas das instituições que mais fortemente reforçam as políticas neoliberais, e os próprios acordos internacionais como o Tratado de Livre Comércio da América do Norte (NAFTA) e o Tratado de Livre Comércio da América Central (CAFTA) enquadram países em "zonas de livre comércio" neoliberais. Embora o neoliberalismo seja "global" neste sentido (de cruzamento de fronteiras nacionais), seus efeitos são muito diferentes em diversas áreas do mundo. Assim como o neoliberalismo intensifica a distância entre ricos e pobres, também pode intensificar a desigualdade entre e sobre as nações, particularmente no contexto das relações pós-coloniais, em que muitas áreas anteriormente colonizadas do mundo já estão em desvantagem econômica. Além disso, o neoliberalismo é um sistema altamente flexível que consegue incorporar uma série de políticas com o objetivo geral de aumentar a privatização, apoiar os mercados e exigir responsabilidade pessoal. Diante dessa flexibilidade, e particularmente por causa dos efeitos diferenciais do neoliberalismo em todo o mundo, eu também quero enfatizar que a ênfase excessiva no casamento entre pessoas do mesmo sexo pode ser útil para o neoliberalismo em algumas áreas do mundo. Por exemplo, o próprio apoio ao casamento entre pessoas do mesmo sexo que ajudou a domesticar sujeitos potencialmente queer como membros responsáveis da família norte-americana pode tornar a oposição a esse casamento uma política vitoriosa em outras áreas do mundo. E, reconhecendo os efeitos táticos do neoliberalismo, também quero considerar algumas das formas que a deficiência pode ser flexivelmente útil para o neoliberalismo. Tanto a deficiência como o queer estavam em evidência no Fórum Social Mundial (FSM) de janeiro de 2007 em Nairobi, Quênia. O FSM é uma reunião periódica e aberta de grupos da sociedade civil

\footnotetext{
${ }^{13}$ Para uma discussão clara e convincente da relação do neoliberalismo com a globalização, ver Dolhinow (2010).
} 
comprometidos com a ideia de que "outro mundo é possível". Originalmente pensado como uma alternativa direta ao encontro anual das elites do capitalismo global em Davos, na Suíça (isto é, o Fórum Econômico Mundial), o FSM tem se tornado, ao longo dos anos, cada vez mais autônomo por direito próprio. No espírito experimental de abertura radical, as exclusões do FSM foram muito poucas: oficialmente apenas foram barrados o Estado, corporações multinacionais, grupos armados e instituições financeiras internacionais (Banco Mundial, Fundo Monetário Internacional, Organização Mundial do Comércio).

Fiquei satisfeito ao ouvir de outro amigo que participou (como eu participei) que um camarada seu tinha sugerido que se alguma coisa estava excitante no Fórum Social Mundial de 2007, eram os grupos queer e da deficiência. O comentário foi brincalhão e irônico, mas também um pouco verdadeiro, e particularmente verdadeiro em relação ao queer, dada a emoção que circulou em torno do "Ponto Q", organizado pela Coalizão Gay e Lésbica do Quênia. A deficiência também apareceu em todos os lugares do FSM, mas em contraste com o que eu sugeri sobre o movimento LGBT hegemônico dos Estados Unidos, a eliminação do queer (e a aceitação do casamento entre pessoas do mesmo sexo ) não foi acompanhada de um desprezo pela deficiência; ao invés disso, no fim, o queer foi repudiado (e o casamento LGBT denunciado) ao lado da incorporação ou uso ${ }^{14}$ às vezes problemático da deficiência.

A deficiência, não o queer, era - de forma improvável, mas discernível - o sinal mágico do neoliberalismo em Nairóbi. A deficiência proporcionou um local para o uso extensivo de uma linguagem da "pobreza" e do "desenvolvimento", que é também a linguagem das políticas promulgadas por instituições neoliberais como o Banco Mundial. Indiscutivelmente, se o Banco Mundial conseguiu um lugar na mesa do FSM de 2007, foi porque a deficiência the garantiu uma entrada. As formas em que a deficiência poderia ser tanto o local de um movimento ativista quanto a extensão do neoliberalismo em um espaço que foi especificamente formado para Ihe fornecer uma alternativa - outro mundo - deve sublinhar o que eu afirmei sobre a flexibilidade e contingência deste sistema predatório. Para dar uma nova interpretação a um conhecido mote dos estudos sobre

\footnotetext{
14 NT: destaque em itálico no original.
} 
deficiência - "todos nós nos tornaremos deficientes se vivermos tempo suficiente" - todos poderemos nos tornar o sinal mágico do neoliberalismo se vivermos o suficiente.

Em contrapartida, o queer foi o sinal mágico daquilo que levantou suspeitas para alguns partidos e observadores do FSM. Os efeitos flexíveis e diferenciados do neoliberalismo mostraram que lançar suspeitas sobre o queer funcionou de forma diferente no contexto do FSM e da nação anfitriã, Quênia, do que nos Estados Unidos. Nos Estados Unidos os queers podem ser denunciados, em parte por não estarem dispostos a seguir a agenda doméstica "razoável" do casamento entre pessoas do mesmo sexo. A associação com os aspectos indisciplinados do queer (e o espectro dos múltiplos parceiros ou relações promíscuas) é usada para atacar campanhas favoráveis ao casamento entre pessoas do mesmo sexo. No FSM e no Quênia, a associação com o casamento LGBT foi usada para denunciar a própria organização queer. Não incidentalmente, os queers que foram repudiados em Nairóbi, em contraste com a maioria dos que fizeram um pedido de aceitação e reconhecimento no imaginário dos EUA, eram em grande parte mulheres ou pessoas trans - Judith Ngunjiri, Emmanuel Kamau (também conhecida como "Tia Ivy") e outras mulheres ou pessoas queer da Coalizão de Gays e Lésbicas do Quênia foram as principais organizadoras do Ponto $\mathrm{Q}^{15}$ do Fórum Social Mundial. E o casamento LGBT era apenas a última coisa em suas mentes: "conheça pessoas $Q$ de todo o mundo", dizia o folheto, "beba uma xícara de chá com seus novos amigos $Q$, ouça quenianos $Q$ contarem suas histórias de vida, leia panfletos $Q$, ouça poesia $Q$, assista filmes $Q$, veja arte $Q$, preste respeito aos heróis $Q$, dance ao som da música $Q$, faça um teste de HIV e aconselhamento com profissionais amigavelmente $Q^{\prime \prime}$. Além disso, as sessões realizadas no Ponto $Q$ raramente mencionavam casamento: Dorothy Aken'Ova, da Nigéria, falou sobre o feminismo lésbico da África Ocidental, o prazer sexual das mulheres e a recuperação e reconstrução das sexualidades africanas; Viktor Mukasa, de Uganda, falou sobre transgressão de gênero e ativismo trans radical; outros falaram sobre coalizões entre grupos lésbicos da África Oriental ou grupos LGBT sul-americanos. E quase todos ligavam essa luta "Q" à justiça social de forma mais ampla: à justiça ambiental, à oposição ao neocolonialismo das corporações multinacionais, aos movimentos dos moradores das favelas.

${ }^{15} \mathrm{NT}$ : A letra Q nas linhas subsequentes do texto é referente ao termo queer. 
No entanto, o casamento entre pessoas do mesmo sexo estava espectralmente presente no Ponto Q. Suas sessões estavam lotadas, mas no quadro geral ainda era uma parte relativamente pequena do FSM. Vocês não saberiam disso com base nos artigos diários da imprensa queniana (ou, ainda mais flagrante, na resposta hostil de vários outros grupos de contra-globalização no FSM); vocês pensariam que um golpe $Q$ estava acontecendo ao virar da esquina. "Agora os gays quenianos buscam reconhecimento", dizia uma manchete. $\mathrm{O}$ artigo começava assim: "Os gays e lésbicas quenianos querem que o Estado reconheça e permita que eles se casem" (NOW KENYAN..., 2007). Dado esse posicionamento semelhante dos quenianos queers com os de gays e lésbicas ocidentais pensando em nada além do casamento, buscando o reconhecimento do "Estado" (lembre-se, é claro, de que "o Estado" nem sequer deveria estar no FSM) - talvez não seja surpreendente que a acusação perene de "anti-africano" circulasse em torno desses ativistas e palestrantes. Minha própria observação, no entanto, se espelhou em Stephen Barris, da Associação Internacional Gay e Lésbica (ILGA):

Os jornalistas se apressaram a informar sobre o Ponto $Q$, mas também começaram a espalhar desinformação, escrevendo que os gays quenianos queriam principalmente o casamento. [Por causa do movimento gay ocidental], os meios de comunicação, os políticos e também o público ouviam 'casamento' toda vez que os direitos LGBT eram mencionados. Mas o casamento está muito abaixo na [lista de] prioridades dos membros da GALCK [Coalizão de Gays e Lésbicas do Quênia], que buscam direitos básicos (BARRIS, 2007).

Às vezes suas preocupações eram estritamente sobre segurança e abertura: Ngunjiri relatou estar muito mais preocupado com sua fotografia e o curso dos seus estudos na Universidade de Nairóbi do que com o que está sendo impresso no jornal sobre "casamento", e que na dança do Ponto $Q$ no domingo à noite nenhuma fotografia foi permitida. Mas se às vezes o foco na integridade física e subjetiva era priorizado, em outros momentos a prioridade era nitidamente ampliar o horizonte de desejos e expectativas queer. Contrariamente às afirmações dos meios de comunicação populares, a dança do Ponto $Q$, com ativistas queer de toda a África, era precisamente um fazermundo porque as possibilidades que incorporou não eram idênticas aos apelos (para a 
aceitação, assimilação, tolerância e casamento) apresentados pela política LGBT neoliberal no Ocidente ${ }^{16}$.

A deficiência no FSM não foi tão diretamente repudiada pelos poderes instituídos (Estado ou mídia), apesar do pesadelo da falta de acesso do Centro Kasarani, onde os eventos foram realizados, e de Nairóbi em geral. Em contraste, na verdade parecia haver uma ênfase (para muitos dos grupos de deficiência presentes) na inclusão sob a garantia do Estado e nas proteções constitucionais. Esse foco foi particularmente interessante à luz dos fracassos magistrais da Lei dos Americanos com Deficiência ${ }^{17}$ (mais de três quartos das reivindicações feitas com este documento são ganhos pelos empregadores), mas também à luz de muitos dos sinais improvisados no FSM, incluindo "Constituições Aristocráticas Nacionais Justificam a Pobreza"18.

Não foi a ênfase nas proteções constitucionais precisamente (ou inteiramente) o que me incomodou, no entanto, tanto quanto a sensação de que algumas das sessões sobre deficiência - muito bem recebidas - pareciam estar falando uma linguagem parcialmente elaborada pelo Banco Mundial: "as pessoas com deficiência em todos os lugares estão excluídas do processo de desenvolvimento e pelas principais organizações de desenvolvimento", "a deficiência é uma das principais causas da pobreza no mundo em desenvolvimento". Não é que essas afirmações não tenham o toque do senso comum

${ }^{16}$ Quero que essas reflexões sobre a dança do Ponto $Q$ ecoem juntas a uma série recente de análises aleijadas do poder da dança no fazer-mundo; ver especialmente Simi Linton (2007) e Sharon L Snyder e David T. Mitchell (2006).

17 NT: O ADA é uma legislação aprovada no congresso estadunidense em 1990 e que, desde então, visa garantir os direitos civis da população norte-americana com deficiência. Essa lei busca principalmente proteger da discriminação as pessoas em razão de sua deficiência.

18 As falhas do ADA conduziram a sua Lei de Restauração de 2007, que evoluiu ao longo de um ano e foi assinada como a Lei das Emendas do ADA de 2008, em 25 de setembro de 2008. A Lei das Emendas tenta inverter a interpretação cada vez mais limitada de quem conta como "deficiente" e que pode reivindicar estar sob proteção do ADA. A interpretação mais limitada tinha sido codificada nos últimos 18 anos pela maioria conservadora da Suprema Corte dos Estados Unidos. A Lei de Emendas entrou em vigor em 1 de janeiro de 2009, e várias coisas ainda estão por ser vistas: o efeito que a Lei de Emendas terá; O grau em que a administração do presidente Barack Obama (em contraste com a administração de George W. Bush) defenderá o ADA e a Lei de Emendas; E como ou se o círculo eleitoral da Suprema Corte, encarregado de interpretar esses documentos, irá mudar nos próximos anos. Apesar destas incógnitas, o meu ponto de vista na conclusão deste ensaio é afirmar que a estratégia progressista, baseada no Estado, do movimento dos direitos das pessoas com deficiência tem seus limites e que um movimento cada vez mais global precisa continuar desafiando esses limites (por exemplo, trabalhadores informais que geralmente não são abrangidos por uma abordagem baseada no Estado). 
sobre elas; o que apenas questiono, para invocar uma distinção feita por Antonio Gramsci, é como e onde esse senso comum está funcionando e como e onde está bloqueando o bom senso.

O Banco Mundial se apressou a adotar um modelo "multifatorial" para reduzir a "pobreza" e aumentar o "desenvolvimento". Este modelo não fala absolutamente nada sobre o capitalismo, mas sim sobre a suposta ampla gama de fatores que "causam" a pobreza. É surpreendente quão frequente e rapidamente a ideia de que "a deficiência está relacionada à pobreza" torna-se "a deficiência causa a pobreza" e quão eficazmente essa tese impede tanto uma crítica ao capital e, mais importante, a possibilidade de que a deficiência possa ser um local subjetivo a partir da qual podemos lançar tal crítica ${ }^{19}$. No entanto, a discussão de alternativas é sem dúvida o próprio propósito do FSM, que foi concebido como uma contraposição à doutrina thatcherista da TINA, "Não há alternativa" ("There Is No Alternative"). Nessa dimensão específica, uma vez que a intervenção e o bloqueio da discussão de alternativas são exatamente o que o neoliberalismo precisa, as pessoas com deficiência tornam-se figuras bastante úteis para o Banco Mundial, de uma forma que os queers do Ponto Q não são ${ }^{20}$.

Nem o queer nem a deficiência são monolíticos. Meu objetivo neste ensaio foi iluminar e criticar a flexibilidade global do neoliberalismo, e destacar os diferentes usos do queer e da deficiência - convergentes ou divergentes, não sendo mais possível dizer só uma coisa sobre ambos. Mas o fato de não ser mais possível dizer que eles são monolíticos não é nem um pouco derrotista, mas sim um insight queer-aleijado crucialmente importante: estamos criando continuamente uma infinidade de maneiras de ser queer e aleijado, e de estarmos juntos. Se esperamos por outro mundo que não seja apenas possível, mas também habitável, podemos e devemos continuar a criar mais.

\footnotetext{
19 Para um exemplo incrivelmente direto desses processos, consulte: World Bank (2007). As palavras "capitalismo" e "neoliberalismo" nunca aparecem no documento de 95 páginas, embora uma seção inteira considere ostensivamente "deficiência e pobreza". Veja minha análise deste documento em McRuer (2007).

${ }^{20}$ Esses pensamentos sobre as formas pelas quais uma figuração de deficiência desautoriza a possibilidade de que a deficiência possa ser um local subjetivo de crítica ao capital devem-se aos argumentos de Roderick A. Ferguson (2004) sobre como a prostituta racializada desempenha uma função semelhante nas discussões do capitalismo a partir de um intervalo das perspectivas políticas.
} 


\section{Referências}

BARRIS, S. Respect for all! Another world is possible for African LGBT people, too. PeaceWork, [S. I.], v. 374, apr. 2007.

CHASIN, A. Selling out: the lesbian and gay movement goes to market. New York: Palgrave, 2001.

DOLHINOW, R. A jumble of needs: women's activism and neoliberalism in the colonias of the southwest. Minneapolis: University of Minnesota Press, 2010.

DUMÉNIL, G.; LÉVY, D. The neoliberal (counter-) revolution. In. SAAD-FILHO, A.; JOHNSTON, D. (ed.). Neoliberalism: a critical reader. London: Pluto, p. 09-19, 2005.

DUGGAN, L. The twilight of equality? neoliberalism, cultural politics, and the attack on democracy. Boston: Beacon Press, 2003.

DUGGAN, L. After neoliberalism? from crisis to organizing for queer economic justice. The Scholar \& Feminist Online, New York, v. 10, p. 1-2, 2012.

FERGUSON, R. A. Aberrations in black: toward a queer of color critique. Minneapolis: $U$ of Minnesota Press, 2004.

FRASER, N. Justice interruptus: critical reflections on the "postsocialist" condition. New York: Routledge, 1997.

GAVÉRIO, M. A. Medo de um planeta aleijado? notas para possíveis aleijamentos da sexualidade. Áskesis, São Carlos, v. 4, p. 103-117, 2015.

HARDT, M.; NEGRI, A. Empire. Cambridge: Harvard UP, 2000.

HARDT, M.; NEGRI, A. Multitude: war and democracy in the age of empire. New York: Penguin, 2004.

LINTON, S. My body politic: a memoir. Ann Arbor: University of Michigan Press, 2007.

LOPES, D. Terceiro manifesto camp. In: LOPES, D. O homem que amava rapazes e outros ensaios. Rio de Janeiro: Aeroplano, p. 95-100, 2002.

MCRUER, R. Crip theory: cultural signs of queerness and disability. New York: New York University Press, 2006.

MCRUER, R. Taking It to the bank: independence and inclusion on the world market. Journal of Literary Disability. Liverpool, v.1, n. 2, 2007.

MELLO, A. G. Dos pontos de vista antropológico, queer e crip: corpo, gênero e sexualidade na experiência da deficiência. In: GROSSI, M.; FERNANDES, F. (org.). A força da "situação" de campo: ensaios sobre antropologia e teoria queer. Florianópolis: EdUFSC, 2018. 
MELLO, A. G.; GAVERIO, M. A. Facts of cripness to the Brazilian: dialogues with Avatar, the film/Fatos da aleijadice à brasileira: diálogos com Avatar, o filme. Anuário Antropológico, Brasília, v. 44, n. 1, p. 43-65, 2019.

NOW KENYAN gays seek recognition. Daily Nation, Nairobi, 22 jan. 2007.

SNYDER, S. L.; MITCHELL, D. T. Cultural locations of disability. Chicago: University of Chicago Press, 2006.

SONTAG, Susan. Notes on "Camp". In: Camp: Queer Aesthetics and the Performing Subject: A Reader. Edinburgh University Press, p. 53-65, 1999.

WORLD BANK. Social analysis and disability: a guidance note. incorporating disabilityinclusive development into bank-supported projects. Washington: World Bank, 2007.

Recebido em: 31 jul. 2020

Aceite em: 17 set. 2020 